\title{
Investigating Active Deformation in the Northern Longitudinal Valley and City of Hualien in Eastern Taiwan Using Persistent Scatterer and Small-Baseline SAR Interferometry
}

\author{
Jiun-Yee Yen ${ }^{1, *}$, Chih-Heng Lu ${ }^{2}$, Chung-Pai Chang ${ }^{3}$, Andrew John Hooper ${ }^{4}$, Yo-Ho Chang ${ }^{1}$, \\ Wen-Tzong Liang ${ }^{5}$, Tsui-Yu Chang ${ }^{6}$, Ming-Sheng Lin ${ }^{2}$, and Kun-Shan Chen ${ }^{3}$ \\ ${ }^{1}$ Institute of Earth Sciences, National Dong Hwa University, Hualien, Taiwan \\ ${ }^{2}$ Department of Natural Sciences, Taipei Municipal University of Education, Taipei, Taiwan \\ ${ }^{3}$ Center for Space and Remote Sensing Research, National Central University, Jongli, Taiwan \\ ${ }^{4}$ Department of Earth Observation and Space Systems, Delft Institution of Technology, Delft, The Netherlands \\ ${ }^{5}$ Institute of Earth Sciences, Academia Sinica, Taipei, Taiwan \\ ${ }^{6}$ Institute of Oceanography, National Taiwan University, Taipei, Taiwan
}

Received 26 February 2010, accepted 25 October 2010

\begin{abstract}
Rapid convergence between the Eurasian plate and the Philippine Sea plate in the northern Longitudinal Valley near the city of Hualien in eastern Taiwan has produced prominent fault scarps and large earthquakes $(M \geq 7)$. This study attempts to more thoroughly understand the surface deformation activities near the faults and their relation to earthquakes near Hualien City using a stable target, multi-temporal radar interferometry method to extract the surface deformation information in this area. Our results indicate that the extracted deformation signals were comparable with those in our leveling data and have a very high spatial density (exceeding 70 point $\mathrm{km}^{-2}$ ). Additionally, all faults in the northern Longitudinal Valley and Hualien City were not deformed monotonically. Rather, deformation time series are complex and frequent activities affected the general trends wherein, for example, 2005 earthquake swarm produced more than $10 \mathrm{~mm}$ of displacement near the Milun fault. Moreover, deformation rates in the study area generally ranged from around $10-20 \mathrm{~mm} \mathrm{yr}^{-1}$ of relative displacement rates along the radar line of sight between the western part of Hualien City near the Central Range and the eastern part during the decade, while only the Mingyi fault displayed monotonic fault activities with change of displacement rates of approximately $5-10 \mathrm{~mm} \mathrm{yr}^{-1}$ across the fault.
\end{abstract}

Key words: Persistent scatterer, InSAR, Longitudinal Valley, Hualien, Milun Fault

Citation: Yen, J. Y., C. H. Lu, C. P. Chang, A. J. Hooper, Y. H. Chang, W. T. Liang, T. Y. Chang, M. S. Lin, and K. S. Chen, 2011: Investigating active deformation in the northern Longitudinal Valley and City of Hualien in eastern Taiwan using persistent scatterer and small-baseline SAR interferometry. Terr. Atmos. Ocean. Sci., 22, 291-304, doi: 10.3319/TAO.2010.10.25.01(TT)

\section{INTRODUCTION}

Located within the plate boundary between the Philippine Sea plate and the Eurasian plate, the Longitudinal Valley of eastern Taiwan is an area of active deformation, where the Philippine Sea plate changes from subducting northwards beneath the Eurasian plate to colliding with Eurasian plate along the Coastal Range in eastern Taiwan (Fig. 1). Around $30 \mathrm{~mm} \mathrm{yr}^{-1}$ of the $82 \mathrm{~mm} \mathrm{yr}^{-1}$ of the continuous convergence of these two plates is consumed along the col-

\footnotetext{
* Corresponding author

E-mail:jyyen@mail.ndhu.edu.tw
}

lisional boundary (Angelier et al. 1997; Yu et al. 1997), with prominent landscapes (Fig. 2) and surface deformation subsequently created along with many earthquakes in eastern Taiwan (Fig. 3). Although many studies have attempted to quantify tectonic activities and locate the faults through various methods (Yu et al. 1997; Yang 1999; Yu and Kuo 2001), those results are often contradictory. Additionally, many earthquakes occur in this area and may affect the deformation patterns, both spatially and temporally. For instance, during April and June of 2005, a sequence of earthquakes occurred near city of Hualien of the northern end of the Longitudinal Valley. However, the extent and 
magnitude of deformation was not studied largely owing to that the extent and magnitude of deformation related to such events are small and thus difficult to survey and quantify; otherwise, an insufficient number of survey points may be available to derive the surface deformation. Moreover, the surface deformation caused by smaller earthquakes or earthquake swarm without a large event has seldom been addressed. Therefore, this study quantifies surface deformation and fault activities in the northern end of the Longitudinal Valley using a multi-temporal InSAR method over the period from 1996 - 2008.

Geodetic procedures such as leveling and GPS data reflect highly accurate data at discrete points. Such methods generally have a very low station density. In an area with simple surface deformation, low spatial observation density can adequately describe the motion. However, it is insufficient to describe the surface displacement in a tectonically complex region. Space-borne synthetic aperture radar interferometry (InSAR) has become a highly effective means of evaluating surface deformation in a complex tectonic region by achieving high spatial resolution. This advantage is, however, hindered by variation in atmospheric properties, inaccuracy in DEM, and uncertainties in satellite orbits. Several different approaches have been proposed to solve these problems. One algorithm tracks consistent radar scattering points (permanent/persistent scatterer) through time (Fer-

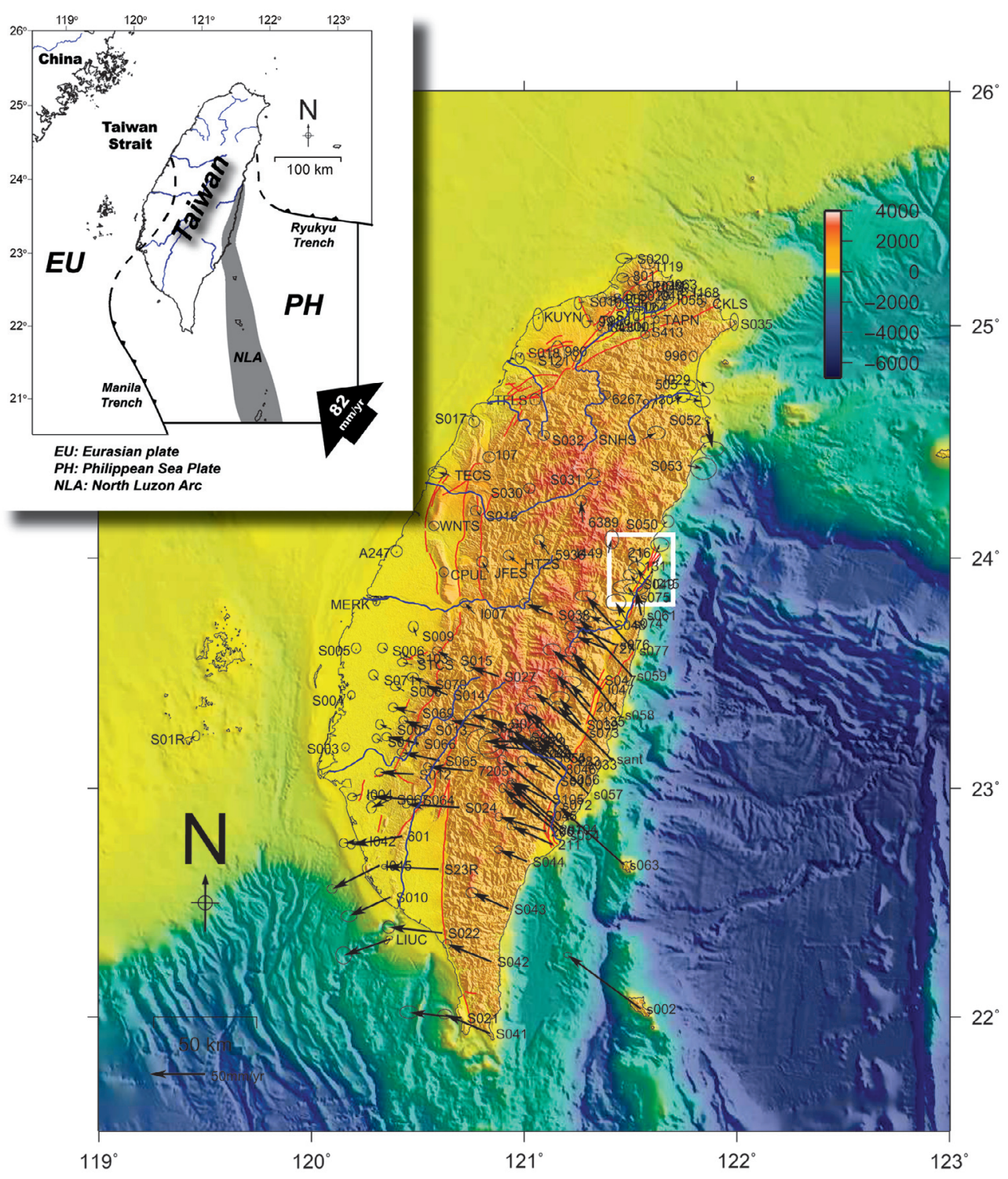

Fig. 1. GPS velocities of Taiwan island. Topleft: Taiwan Tectonic. The Philippine Sea plate is subducting beneath the Eurasian plate to the northeast of Taiwan, while the Eurasian plate is subducting beneath the Philippine Sea plate to the south of Taiwan. The research area (shown by white rectangular frame) is between the northern end of the collided Luzon arc and uplifted continental-derived materials. The GPS Velocity is relative to S01R. Red lines denote the active faults published by the Central Geologic Survey, Taiwan. PH: Philippine Sea plate; EU: Eurasian plate; NLA: North Luzon Arc. GPS Velocity is relative to S01R. Data from DMC, Institute of Earth Sciences, Academia Sinica. 


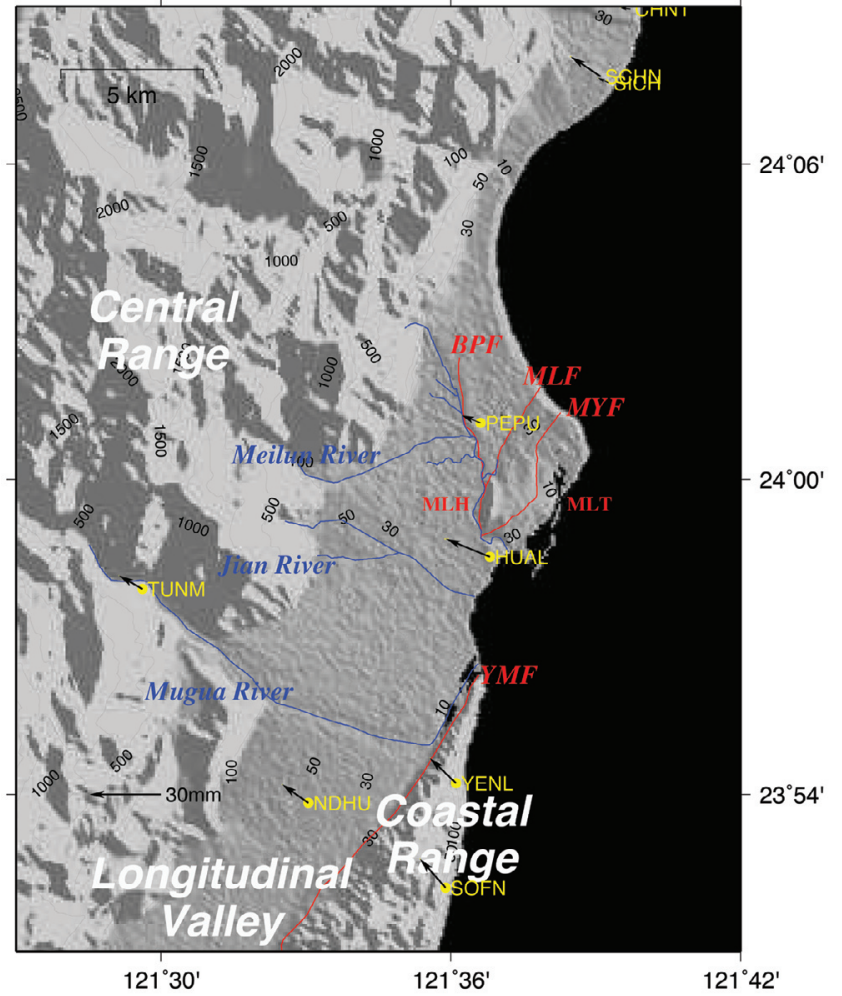

Fig. 2. Topography of the study area (location in Fig. 1). Hualien City and its suburbs are surrounded by the Central Range to its west, the Coastal Range to its southeast, and the Pacific Ocean to the east. In addition to the two mountain ranges, the prominent landscapes near Hualien City are Milun Hill (MLH) and Milun terrace (MLT) that is bordered by the Milun Fault (MLF). Other active features are Beipu Fault (BPF), Mingyi Fault (MYF), and Yuemei Fault (YMF). The GPS Velocity is relative to S01R. Data from DMC, Institute of Earth Sciences, Academia Sinica.

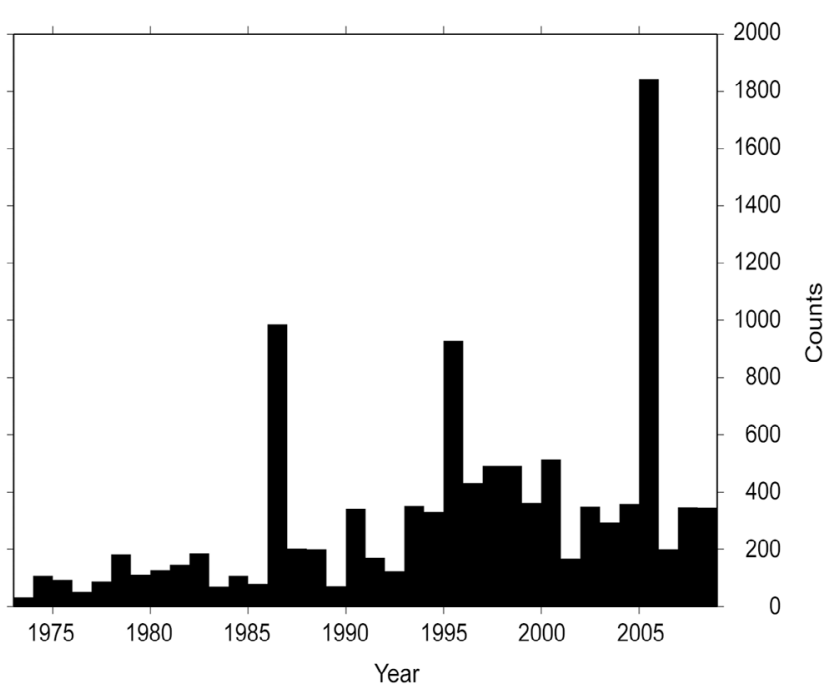

Fig. 3. Number of earthquakes $(M \geq 1)$ vs. time observed within the study area. Although the complete magnitude $\left(\mathrm{M}_{\mathrm{C}}\right)$ is about 2.7 and 2.2 before and after 1985, the high seismicity in 1986 is due to 1986 Hualien event $\left(M_{L}\right.$ 6.8). The number of earthquakes in 2005 in the study area is significantly higher than the background values. retti et al. 2001; Hooper et al. 2007) by using a master image and multiple slave images. The method discards any point not correlated through time and preserves only high quality points, subsequently reducing the complexity and data size significantly. However, this algorithm is limited in that the radar images pair up together even when the pairing condition is not optimal, i.e., large normal baseline between radar image acquisitions. To circumvent this problem, a small baseline subset (SBAS) algorithm (Berardino et al. 2002) limits the orbital separation between radar image pairs, subsequently increasing the coherence of radar interferograms. These two complementary algorithms select different sets of points and derive their respective information independently. As these two algorithms attempt to solve for the motion and average velocity of each PS point, the resulting data can be combined to form a single dataset. This study adopts the multi-temporal InSAR, which combined Persistent scatterer interferometry (PSI) and small baseline subset (SB) procedure (Hooper 2008). The combined PS and SB approach increases the number of data points in the area of study.

This study characterizes surface deformation and its pattern associated with the seismicity of 2005 earthquake swarm by using persistent scatterer InSAR (PS), small baseline subset (SB), and relocation of earthquake events using HypoDD (Waldhauser and Ellsworth 2000). Surface deformation related to this earthquake swarm and after the event is also discussed.

\section{DATA AND METHODOLOGY}

\subsection{ERS, Envisat, and DEM}

Ten Envisat and twenty two ERS satellite radar images were used in this study (as shown in Fig. 4; Both ERS and Envisat radar images are from Track 461, Frame 3123, Image mode). Envisat radar images were taken from May 2004 to February 2008 and ERS radar images were taken from June 1995 to October 2001. Raw radar images were focused using ROI_PAC software developed by the JPL/ Caltech (Rosen et al. 2004). Interferograms were formed using Doris software developed by the Delft University of Technology, the Netherlands. The PSI (Hooper et al. 2007) and SB (Hooper 2008) were processed with StaMPS/MTI. The topography phase component was removed by using SRTM DEM (3 arc second in resolution) during interferogram processing. Since the residual between real topography and DEM can be estimated during PS processing, the results are not very sensitive to the resolution of DEM. The ERS/ Envisat precise orbits from the Technical University of Delft were used to correct for the orbital contribution to phase.

\subsection{PS and Small Baseline}

Differential SAR Interferometry (DInSAR) has become a popular way to determine surface deformation over 

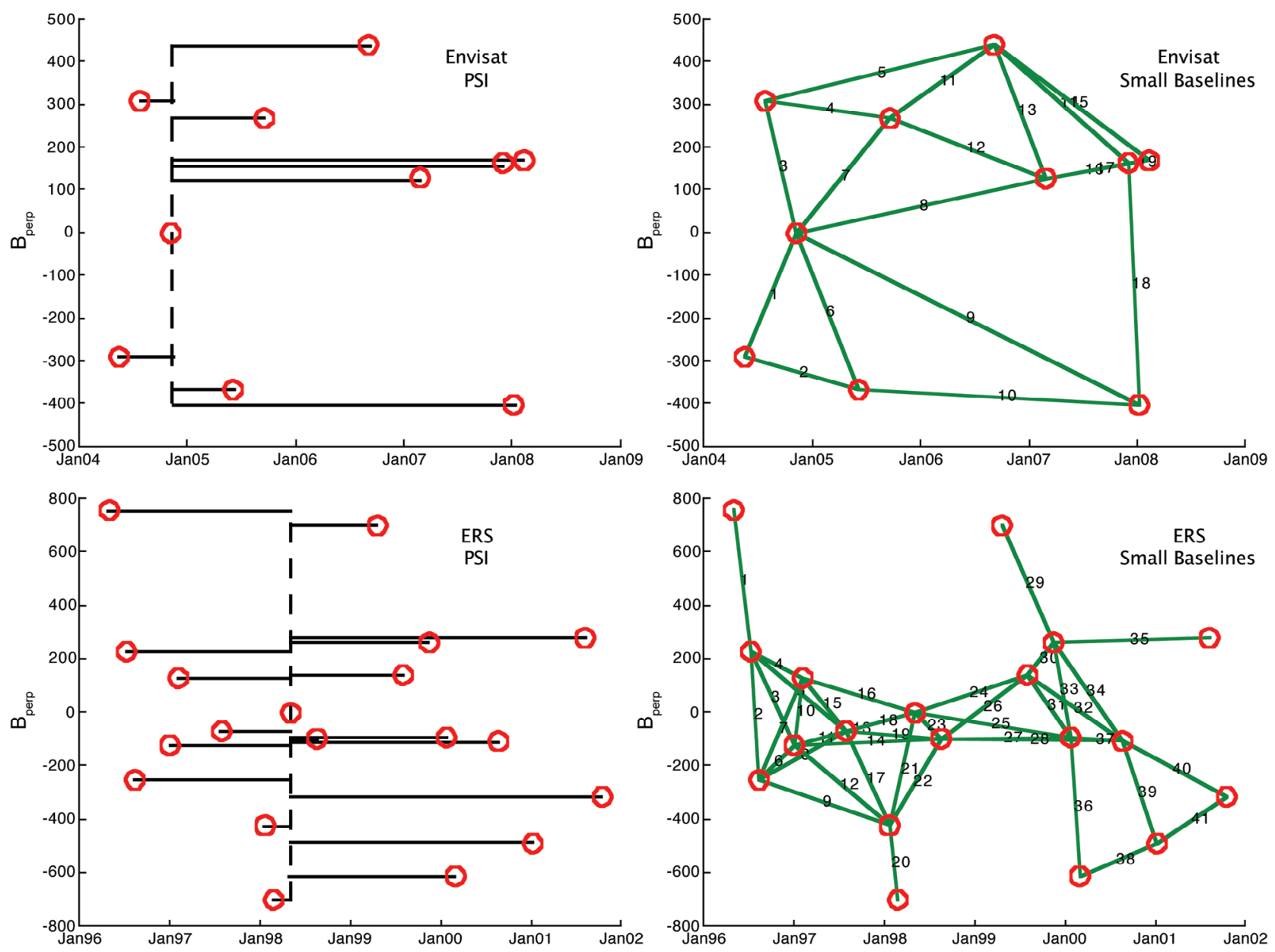

Fig. 4. Radar images and baseline information used in this study. Vertical axes are perpendicular baselines of image pairs, horizontal axes are acquisition dates of radar images.

an area larger than tens of $\mathrm{km}^{2}$. The method is often highly successful, particularly when assessing coseismic deformation (Wright et al. 1999; Chang et al. 2004), where the amount of deformation is often on the order of meters. However, when the amount of deformation is small and distributed over time, the temporal decorrelation of radar signals can often affect DInSAR results wherein no meaningful information can be extracted. Meanwhile, even in an area of coherent radar signals, variations in atmospheric properties and quality of DEM can significantly affect data.

Many approaches have been developed to utilize only radar signals from stable targets to address the decorrelation in atmospheric conditions as well as other noise related problems. Ferretti et al. $(2000,2001)$ first proposed the Permanent Scatterer (PS) method that identifies PS using the 'dispersion index' of radar amplitude images. Several other similar algorithms have been developed to extract PS information (Lyons and Sandwell 2003; Kampes 2006). This method is highly successful in urban areas containing many buildings. However, in the northern Longitudinal Valley of eastern Taiwan, the urban area is small and dispersed with rice patties and fish ponds, with a portion of the area even heavily forested, and preliminary test results indicate that very few stable targets can be extracted from this type of surface area (Lu 2007).

Persistent scatterer interferometry (PSI) was performed in this study using StaMPS/MTI (Multi-Temporal InSAR) developed by Hooper et al. (Hooper 2007; Hooper et al. 2008). PS algorithm involves estimating phase contributions from various terms (Ferretti et al. 2001; Hooper et al. 2007), where the phase from the $\mathrm{x}$-th point in the $\mathrm{i}$-th interferogram is:

$\phi_{i n t, x, i}=\phi_{\text {def }, x, i}+\phi_{o r b, x, i}+\phi_{\varepsilon, x, i}+\phi_{a t m, x, i}+\phi_{n, x, i}$

where $\phi_{\text {def }}$ represents the deformation term; $\Delta \phi_{\varepsilon}$ : DEM error (look angle error); $\Delta \phi_{a t m}$ : phase contribution from atmosphere phase delay; $\Delta \phi_{o r b}$ : error resulting from orbit inaccuracies; and $\phi_{n}$ : general noise (e.g., thermal and coregistration). 
In the equation, deformation and atmosphere terms are correlated spatially, while the atmosphere term is not correlated temporally. However, DEM residuals are nearly the same throughout the entire time span of the data set, and phase contribution from DEM residuals is proportional to the perpendicular baselines. Therefore, mathematical processes can be designed to distinguish between these terms. Notably, PS points are identified by the points with minimal $\phi_{n}$. Initially, a subset of pixels is selected based on the dispersion index $D_{A}$, which is defined by Ferretti et al. (2001),

$D_{A} \equiv \sigma_{A} / \mu_{A}$

where $\sigma_{A}$ and $\mu_{A}$ represent the standard deviation and the mean of amplitude value of a pixel through all images. A value of 0.4 is used to ensure that a large subset of points are selected before performing phase analysis (Hooper et al. 2007), and a value of 0.6 for amplitude difference dispersion $\left(D_{\Delta A}\right)$ is used for SB processing. After a subset of pixels is selected as the initial PS candidates, the phase stability for each PS candidate is estimated through a series of iterations (Hooper 2008).

Spatially correlated terms can be estimated by applying a band-pass filter in the frequency domain over a small area surrounding the PS candidate. Subtracting the filtered phase from the original phase leaves a non-spatially correlated phase contribution; this term correlates with the perpendicular baseline, thus allowing us to determine the DEM contribution by estimating the factor using the leastsquare method. In this study, phases are unwrapped both spatially and temporally (Hooper and Zebker 2007) after phase contributions from DEM residuals are estimated and removed. In practice, the radar images are subsampled to a five meter grid resolution in order to coregister radar images more effectively. The ERS and Envisat datasets were processed using the same parameters and procedures in this study.

\section{RESULTS}

Ten Envisat radar images were used to form 9 PSI interferograms and 24 SB interferograms, and the 22 ERS radar images were used to form 21 PSI interferograms and 43 SB interferograms. Most of the SB interferograms had an absolute normal baseline smaller than $300 \mathrm{~m}$, thus the phase contributions derived from DEM residuals were small even before the SB method removes the DEM residual effects. Many stable point targets were extracted in our study area. Within the $400 \mathrm{~km}^{2}$ of our study area, roughly 39000 stable targets were available (about 27000 were from PS and 11000 from SB, some of the stable targets were extracted by both methods) in the Envisat dataset, around 30000 stable targets were extracted from the ERS dataset (about 8500 from PS and 27000 from SB). This led to more than a 90 and 70 point $\mathrm{km}^{-2}$ in spatial observation density, respectively, and slightly less than $0.25 \%$ of possible points were selected as stable targets. Although more than $99 \%$ of all available image pixels were dropped from the original data (which significantly increases the calculation efficiency), the resulting PS points were still two to three orders of magnitude higher than data points from other geodetic methods.

Some PS points were located offshore in the raw data, particularly in the Envisat dataset. When points were selected using a set of criteria, a small but finite likelihood of 'good' points failed to be selected and 'bad' points successfully slipped into the selected points. The likelihood of miss-selection diminished with an increasing number of radar images (such as in our ERS dataset). Results obtained from the offshore PS points indicated a significantly higher standard deviation over that of the results from the Hualien City area. Additionally, the density of the offshore points is approximately 2 orders of magnitude smaller than that of Hualien City. Therefore, the small amount of lower quality points should not significantly alter the results onland.

\subsection{Deformation Time Series}

Envisat data used in this study ranged from mid 2004 to early 2008 (ERS data were also investigated, but not presented here and are available upon request). The unwrapped results from Envisat radar images were the deformation time series near the northern end of the Longitudinal Valley (Fig. 5). The red color denoted shortening along the radar line-of-sight (LOS, $\sim 23^{\circ}$ from normal) relative to the master $(2004 / 11 / 06)$. Because the radar LOS is only $23^{\circ}$ from vertical, the outcome is more sensitive to vertical motion. The deformation time series revealed complex deformation patterns in the northern end of the Longitudinal Valley and Hualien City. In the southern part of the research area near the Mugua River, the general trend was subsiding (showing an increase in LOS) through time. West of Hualien City and the Beipu fault in the northern part, the area was shortening in LOS in relation to the master image (2004/11/06). East of the Beipu fault and Milun Fault, the deformation was more complex. Specifically, the data from 2005/06/04 indicated an uplift event of $10-20 \mathrm{~mm}$ relative to the master image. This deformation coincides with the earthquake swarm in both time and extent, which is discussed in detail in 4.2. Profile extracted from our combined PSI and SB result (Fig. 6) revealed that the displacement gradient was the largest to the west of the Milun Fault between $1-4 \mathrm{~km}$ in the profile $(\sim 1 \mathrm{~km}$ west of the Beipu fault), subsequently reaching maximum at about $16 \mathrm{~mm}$ relative to the master image (2004/11/06). From June to September 2005, the same area subsided for up to $22 \mathrm{~mm}$ near the Beipu fault and the Milun Fault. From middle of 2005 to early 2008, the area east of the Mingyi fault was subsiding, while the area closer to the Central Range was uplifting. 


\subsection{Mean Velocity}

Figures 7 and 8 illustrate the surface deformation velocity derived from Envisat (2004 - 2008) and ERS (1995 - 2001), respectively, and represented the rates of range change in the LOS direction from Envisat and ERS satellites. The deformation rates are arbitrary against any reference area and can be shifted to an area with known deformation rates (Hualien City was set to zero in both Envisat and ERS datasets). The area to the east of Mingyi fault was subsiding relative to its west at about $1-2 \mathrm{~mm} \mathrm{yr}^{-1}$ from 1995 to 2001, while subsiding at about $4 \mathrm{~mm} \mathrm{yr}^{-1}$ from 2004 to 2008. Notably, south of Hualien City was generally subsiding in comparison with Hualien City, and the area near the Coastal Range was subsiding relative to the area near the Central Range in the Longitudinal Valley.

\subsection{Profiles}

Five profiles were extracted from both Envisat and ERS average LOS velocity data (Fig. 9; Figs. 7 and 8 show the profile locations). East-west trending profiles (profile A through D) generally display a shortening in the radar line of sight in the western end in relation to the eastern end of profiles. The profiles contain several places with a sharp gradient indicating differential surface motion across these places. According to profiles A and B, both the Beipu and Milun Faults were not particularly active during the time spans of these image acquisitions. However, the area to the east of the Mingyi Fault was subsiding relative to the west of the fault at $3-5 \mathrm{~mm} \mathrm{yr}^{-1}$ (right panel in profile B of Fig. 9). Profile $C$ revealed that the fault system in the Milun Terrace of Hualien City may not extend to the south since
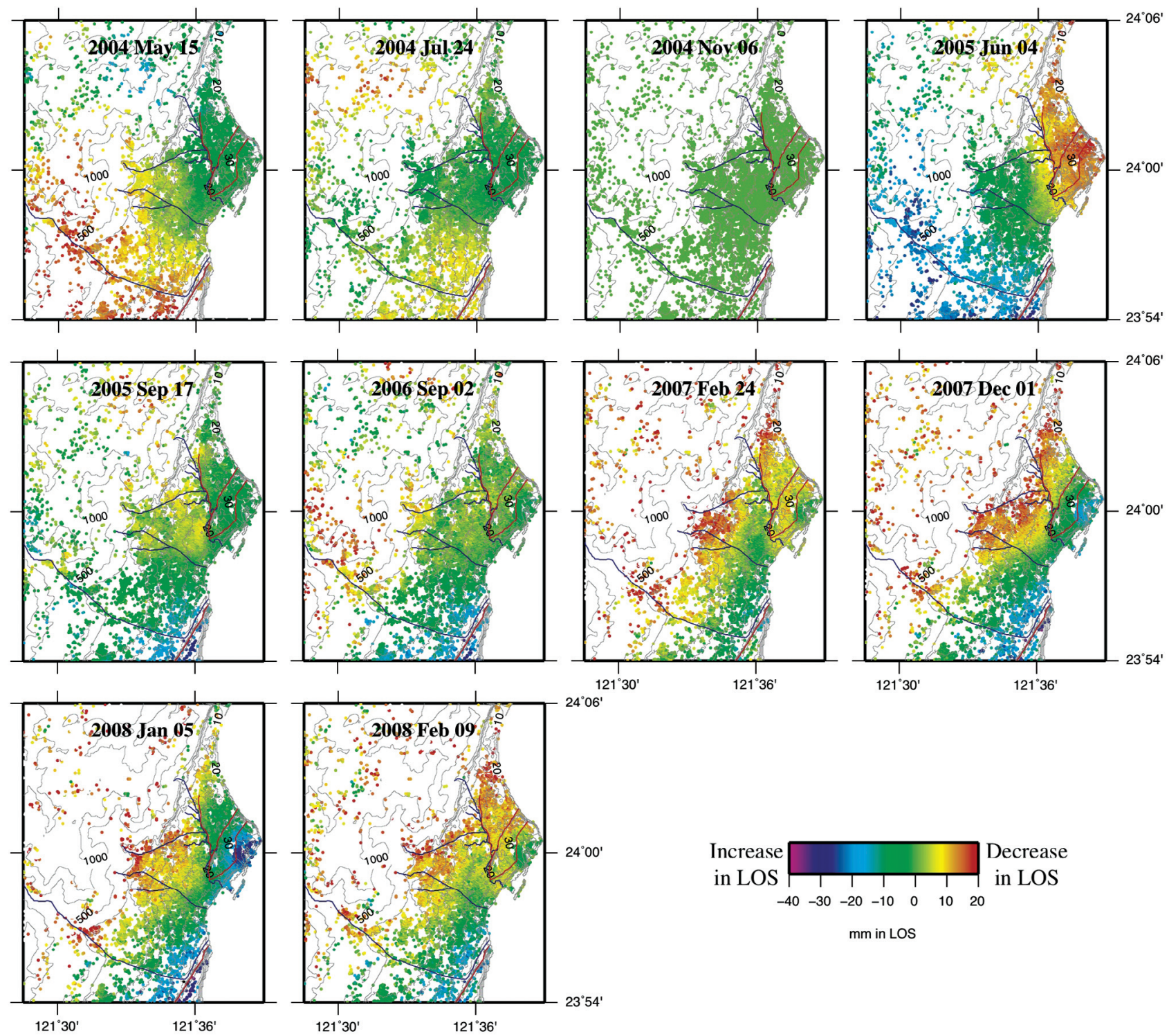

Fig. 5. PSI deformation time series derived from Envisat dataset. The color scale denotes a change in the slant range along LOS. The negative value to positive value represents a range of -40 (shortening) to $20 \mathrm{~mm}$ relative to area with zero value. 
(a) Coseismic LOS 20041106_20050604
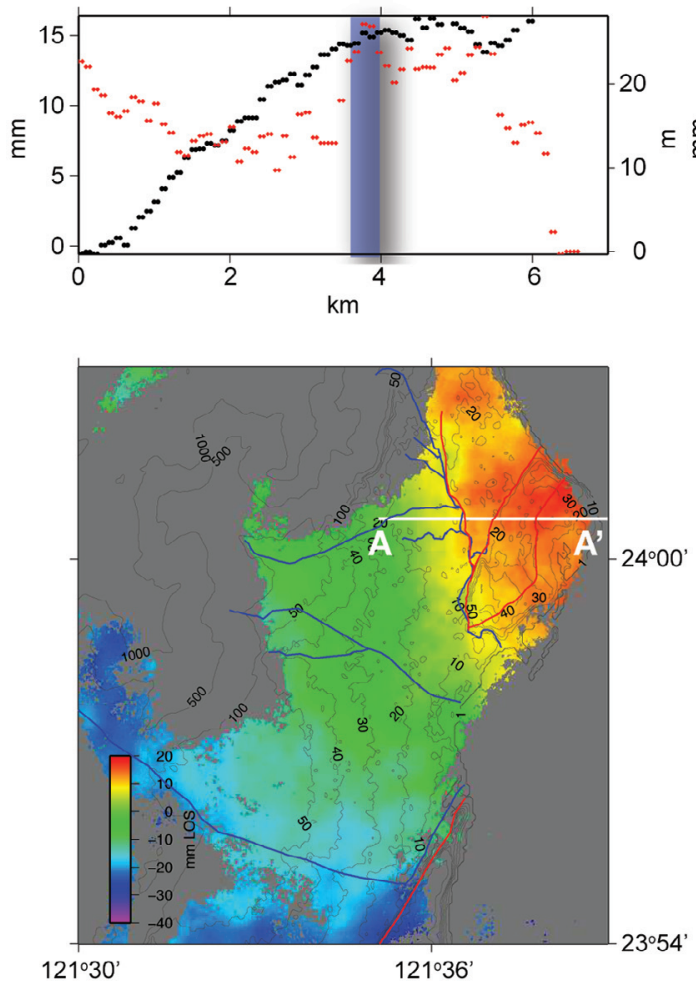

(b) Coseismic LOS 20041106_20050917
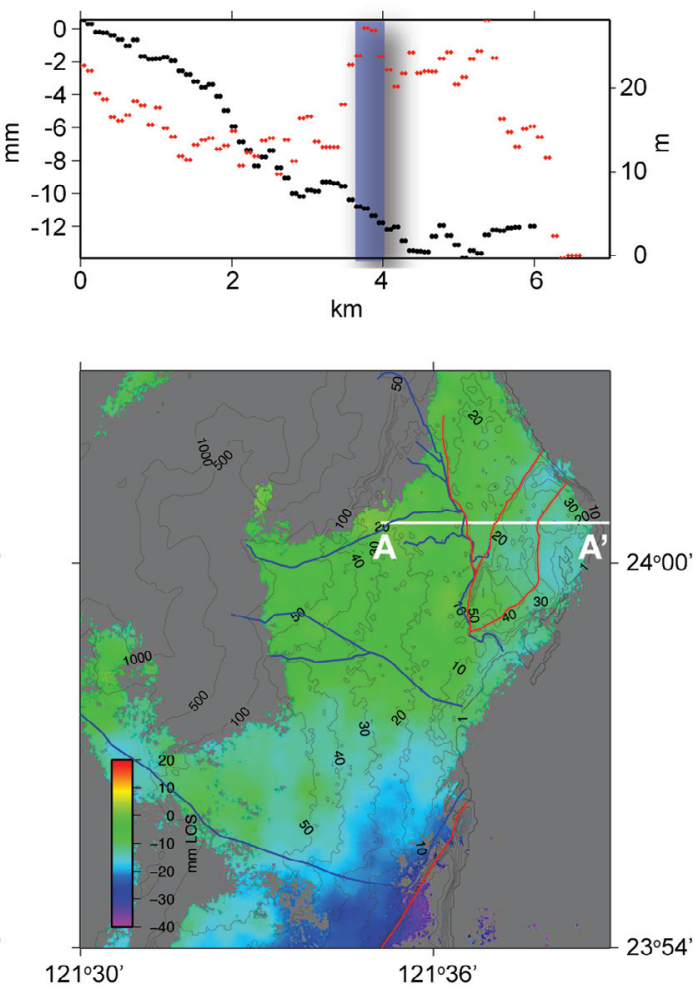

Fig. 6. (a) Coseismic deformation analysis of the Envisat image pair 20041106 and 20050604; (b) Coseismic deformation analysis of the Envisat image pair 20041106 and 20050917; Red dots denote the topography along the profile AA' and black dots represent coseismic deformation along profile AA'.

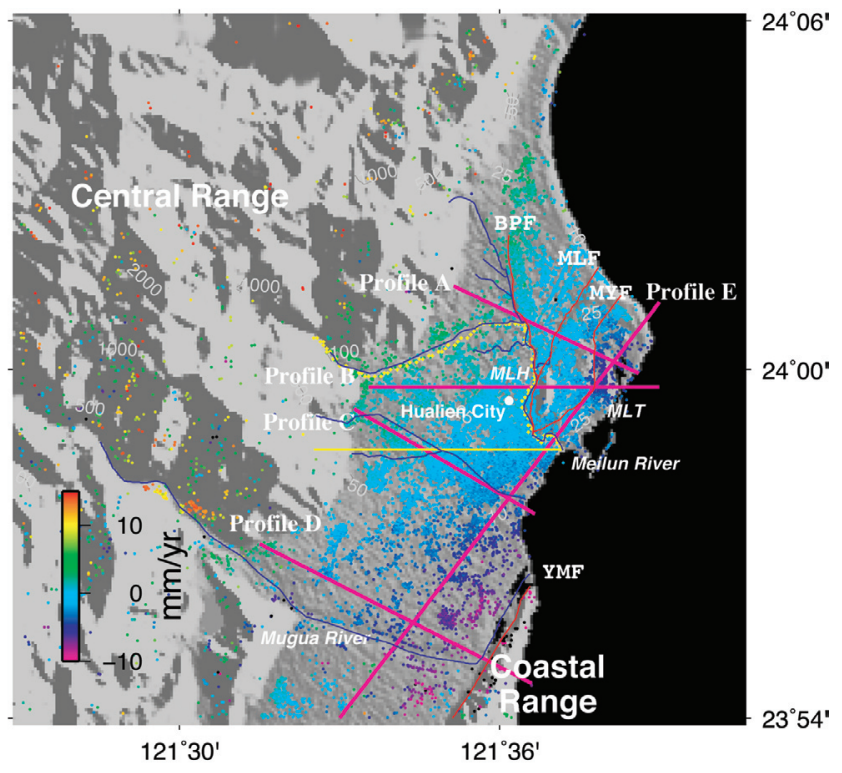

Fig. 7. PSI mean velocity - Envisat. Average LOS (Line-of-sight) velocity near Hualien City derived from Envisat dataset (2004 - 2008). Within the Longitudinal Valley and Hualien City, LOS velocity ranges approximately from $0 \sim-10 \mathrm{~mm} \mathrm{yr}^{-1}$. Relative to Hualien City (white circle) the eastern part of Milun Terrace was subsiding at about $1 \mathrm{~cm}$ $\mathrm{yr}^{-1}$ (BPF: Beipu Fault; MLF: Milun Fault; MYF: Mingyi Fault; YMF: Yuemei Fault; MLH: Milun Hill; MLT: Milun Terrace). Red lines: faults; Magenta lines: profiles; Yellow points: Leveling points along Milun river (Yellow line: see Fig. 13).

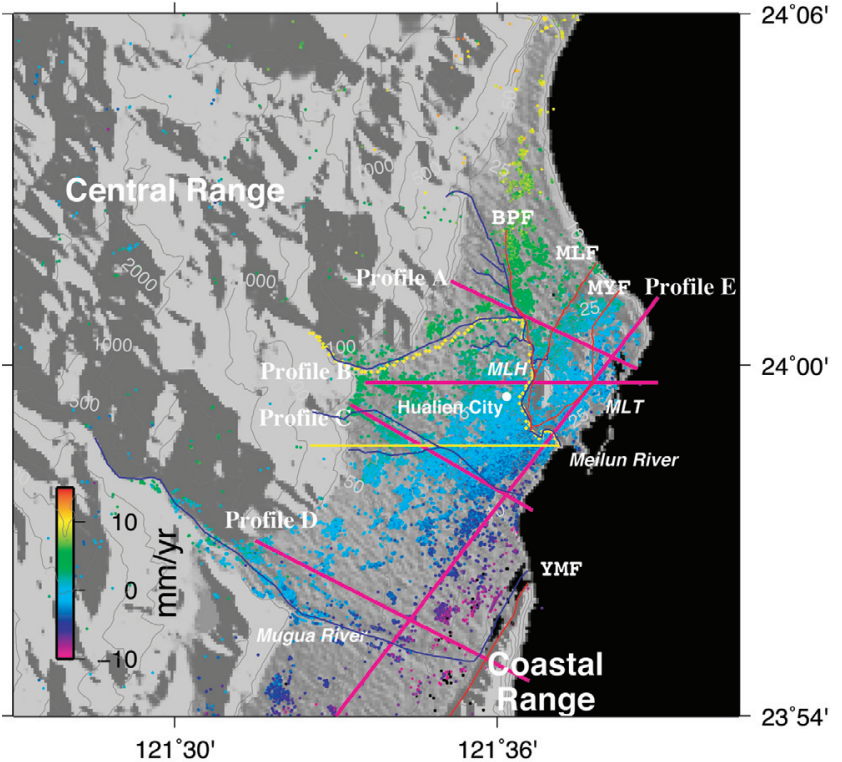

Fig. 8. PSI mean velocity - ERS. Average LOS velocity derived from ERS dataset (1995 - 2001). The western side was in general shortening in LOS direction relative to the eastern side. Fault activities along LOS were not very prominent except for across the Mingyi Fault (MYF). 

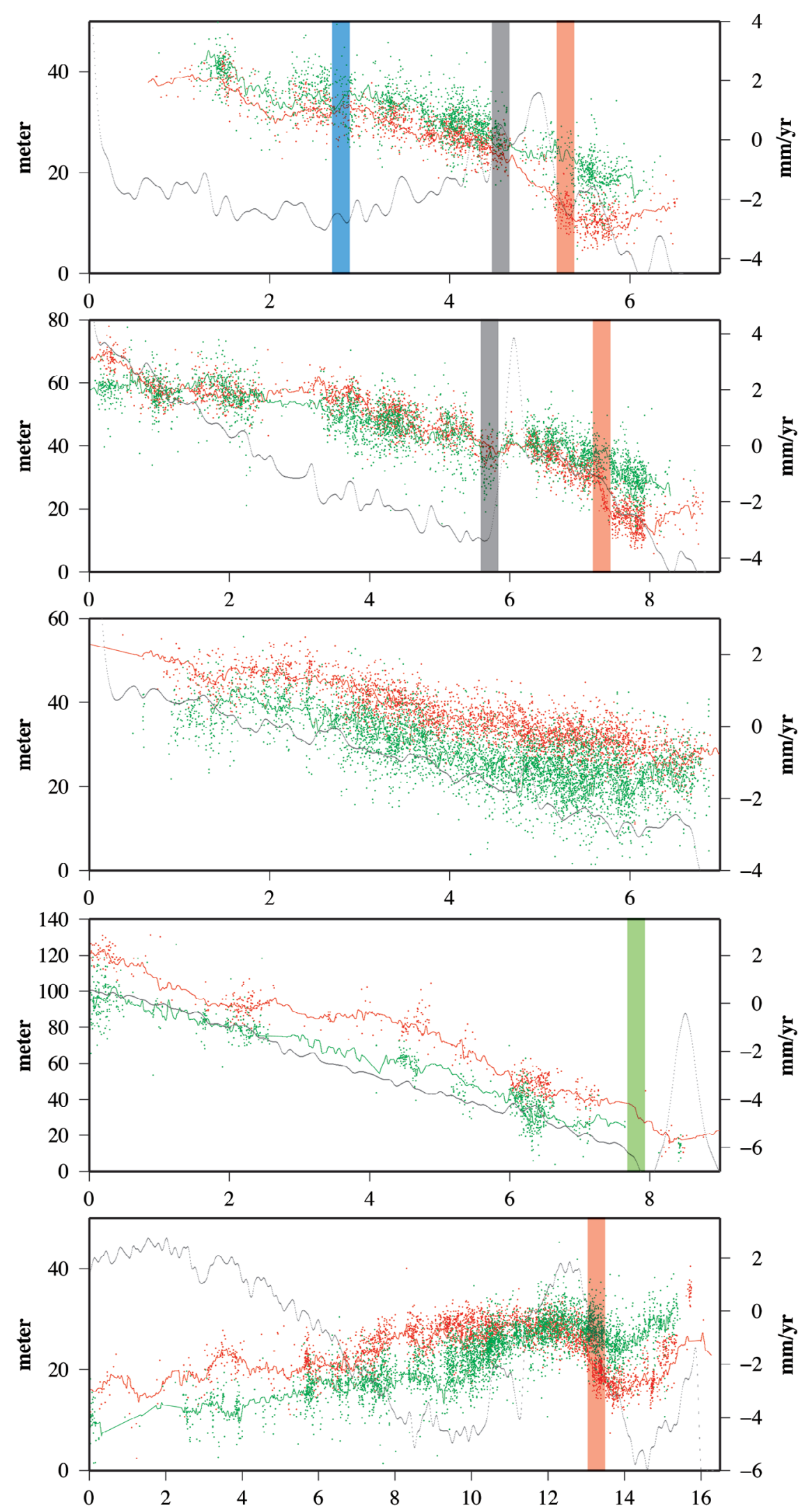

Fig. 9. PSI - profiles (profile locations are from Figs. 7 and 8). Red dots denote individual PS points while the red lines represent interpolated results. Green dots denote the topography along the profile. From profile A - D, the sample width and interpolation search radii for individual points were $500 \mathrm{~m}$, while in profile E 1000 m was used (Velocity scale in ERS differs from that in Envisat. Beipu Fault: light blue; Milun Fault: grey; Mingyi Fault: pink; Yuemei Fault: green). 
the deformation rate increased steadily towards the Central Range without any interference.

Profile D generally resembled profile C except that the former passed through the very northern end of the Coastal Range. According to the results of this profile, the Coastal Range was subsiding slightly $\left(<5 \mathrm{~mm} \mathrm{yr}^{-1}\right.$, LOS $)$ at this section, and the fault trace of the Coastal Range Fault (Yuemei Fault) was within $1 \mathrm{~km}$ of western edge of the Coastal Range. The longitudinal profile $\mathrm{E}$ indicated that Hualien City was uplifting relative to the northern end of the Longitudinal Valley. The deformation gradients are relatively gentle from 3 to $13 \mathrm{~km}$ along profile $\mathrm{E}$, which suggests the fault system may not have significant slip at shallow depth in this section. Both ERS and Envisat datasets indicate that Mingyi Fault was actively deforming during time spans of both ERS and Envisat datasets (profiles A, B, and E). The very high deformation gradient (profiles B and E of Fig. 9) and varying deformation pattern across the Mingyi Fault changes through time (as shown in Fig. 5) suggests the surface deformation is tectonic origin.

\subsection{HypoDD Relocated Earthquake Swarm}

Earthquakes during April and June 2005 were relocated in this study using HypoDD (Waldhauser and Ellsworth 2000). During this period, 1612 events were recorded $\left(121.4-121.8^{\circ} \mathrm{E} ; 23.94-24.126^{\circ} \mathrm{N}\right)$ within $0-35 \mathrm{~km}$ in depth (data from the Taiwan Central Weather Bureau). Of these earthquakes, we relocated 826 earthquakes with HypoDD program (Fig. 10). The result collapsed in to a quasiplanar cluster from the original solutions (Fig. 11). The surface was mainly in a north-northeast direction, sub-parallel to the Longitudinal Valley near Hualien City with a few of the events located not far offshore. Most earthquake events were located between 6 to $14 \mathrm{~km}$ below the surface, while the southern cluster (near profile 5) and offshore cluster
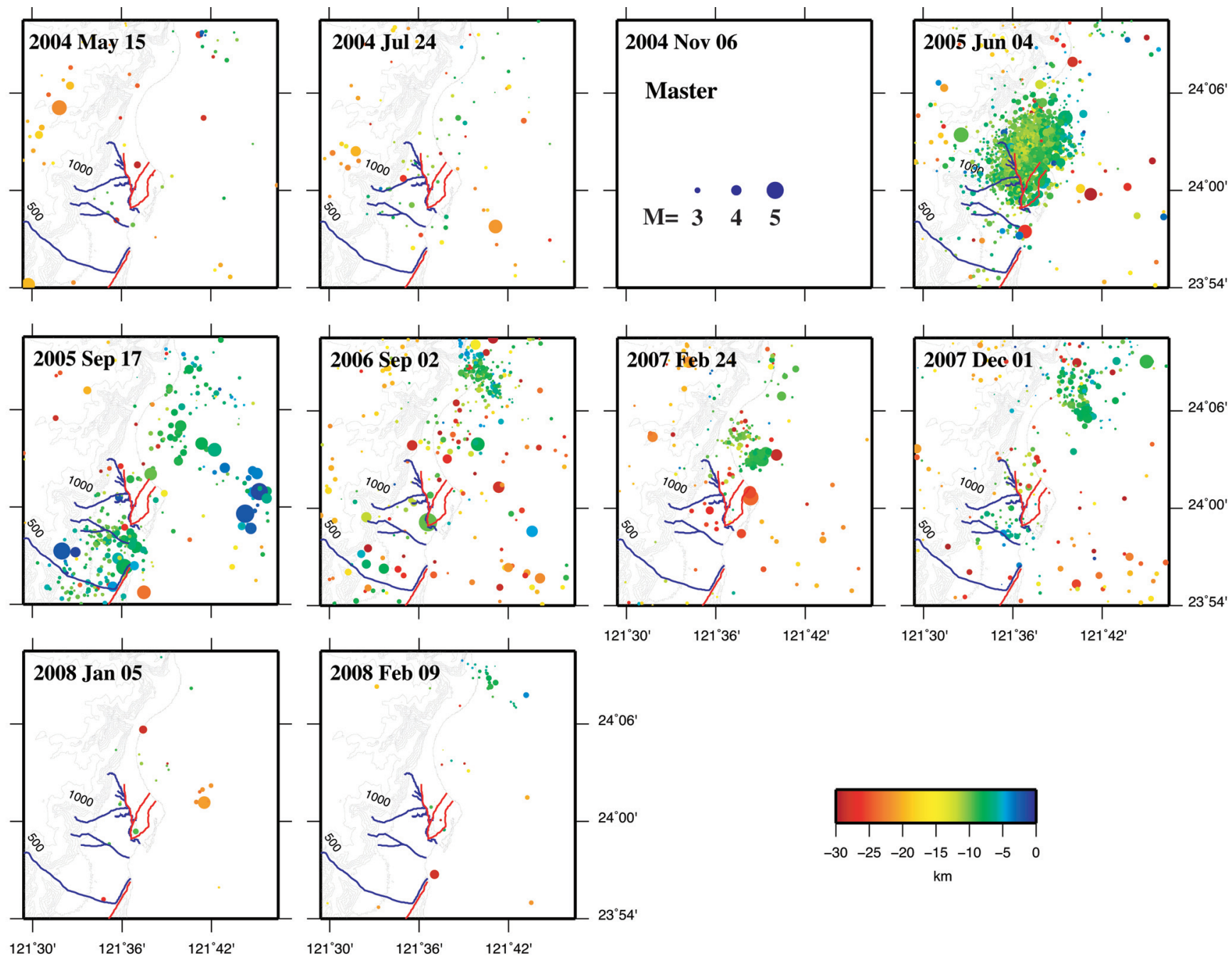

$\mathrm{km}$

Fig. 10. Earthquake time series. Earthquakes near Hualien that were coeval to the Envisat duration were used, along with the data arranged based on the time of radar images. The frequent earthquake activities coincided with the surface deformation in Fig. 5. 


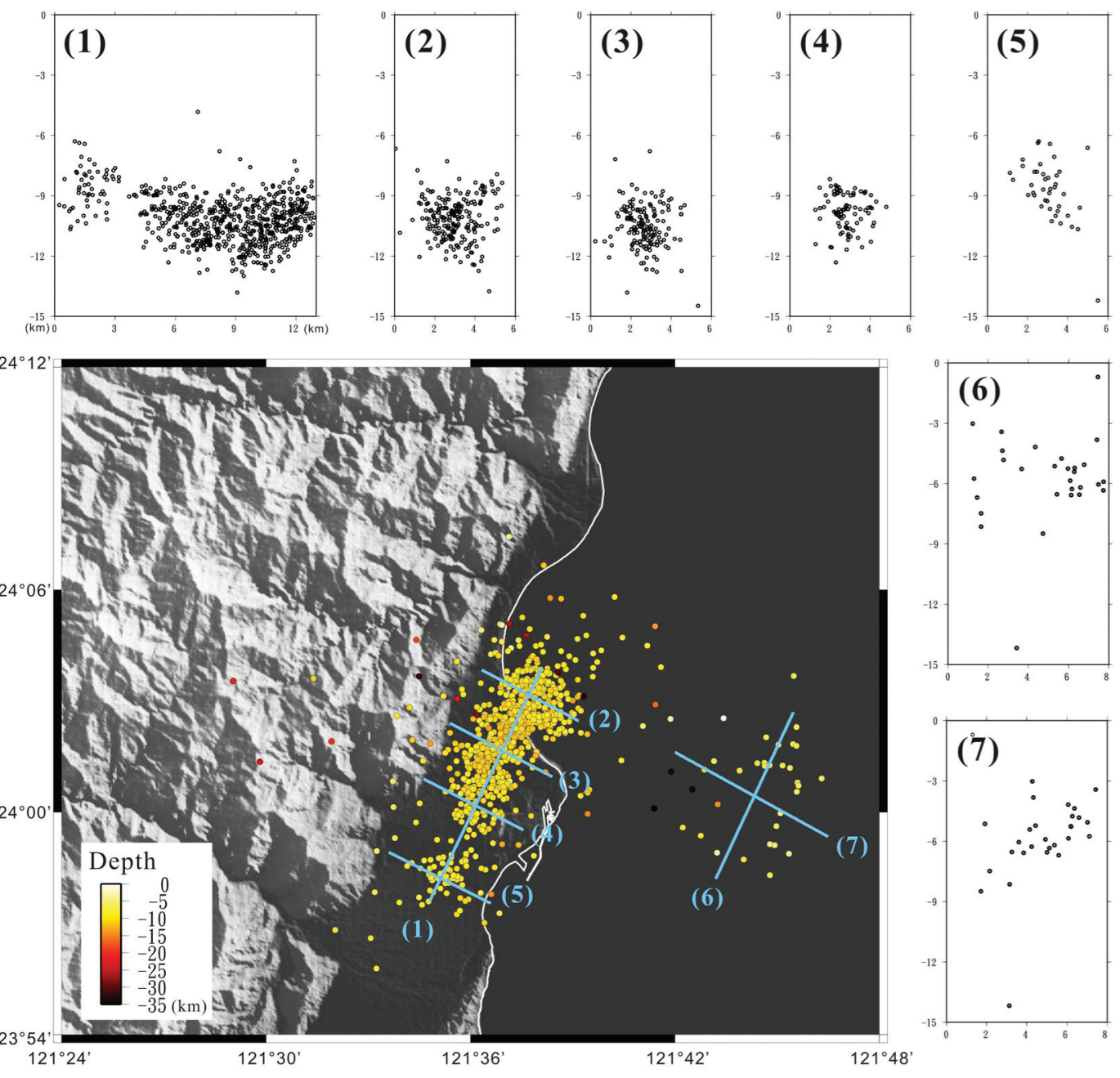

Fig. 11. HypoDD relocated earthquakes. An approximately east dipping quasi-planar cluster can be seen in profiles 2 - 5 .

(profiles 6,7) were shallower than in the main cluster of events. The earthquake events initially concentrated near Hualien City in April 2005 then spread outward in May. Finally, in June 2005, the swarm ended with shallower earthquake events in the south of Hualien City and offshore to the east.

Focal mechanisms from larger events in the swarm revealed that in April, most of the large events were strike-slip earthquakes (Fig. 12). In May, most events were of a thrust nature with the principal stress trending mainly east-west. In June, the larger events in the southern cluster were mainly thrust type while the two larger ones offshore displayed a combined strike-slip and thrust type.

\section{DISCUSSION}

\subsection{Comparisons with Leveling Results}

The Taiwan Water Resource Agency had set up benchmarks along major rivers in Taiwan. A leveling campaign was performed along the Meilun River (Fig. 7, yellow dots) in Hualien City from February 2007 to December 2008. Our MTI results were verified by extracting MTI information at the same locations from leveling benchmarks. The locations of benchmarks were not necessarily selected as persistent scatterers. To avoid missing data, MTI data was first interpolated using the nearest-neighbor algorithm and the interpolation was limited to within $1 \mathrm{~km}$ of existing persistent scatterers. By this method, the area with a high PS density was interpolated while the area with a low PS density was left blank. Both results were projected on an east-west profile (Fig. 7, yellow line) for comparison. Figure 13 compares MTI derived data and leveling derived data. Along the projected profile, the trends between MTI and leveling resembled each other, with a high displacement gradient near the location of Milun Fault and a westward increasing trend of displacement rates. However, more closely examining the data revealed that the deformation rates derived from MTI was roughly half of those from leveling. Differences between these two observations are attributed to the following factors: 

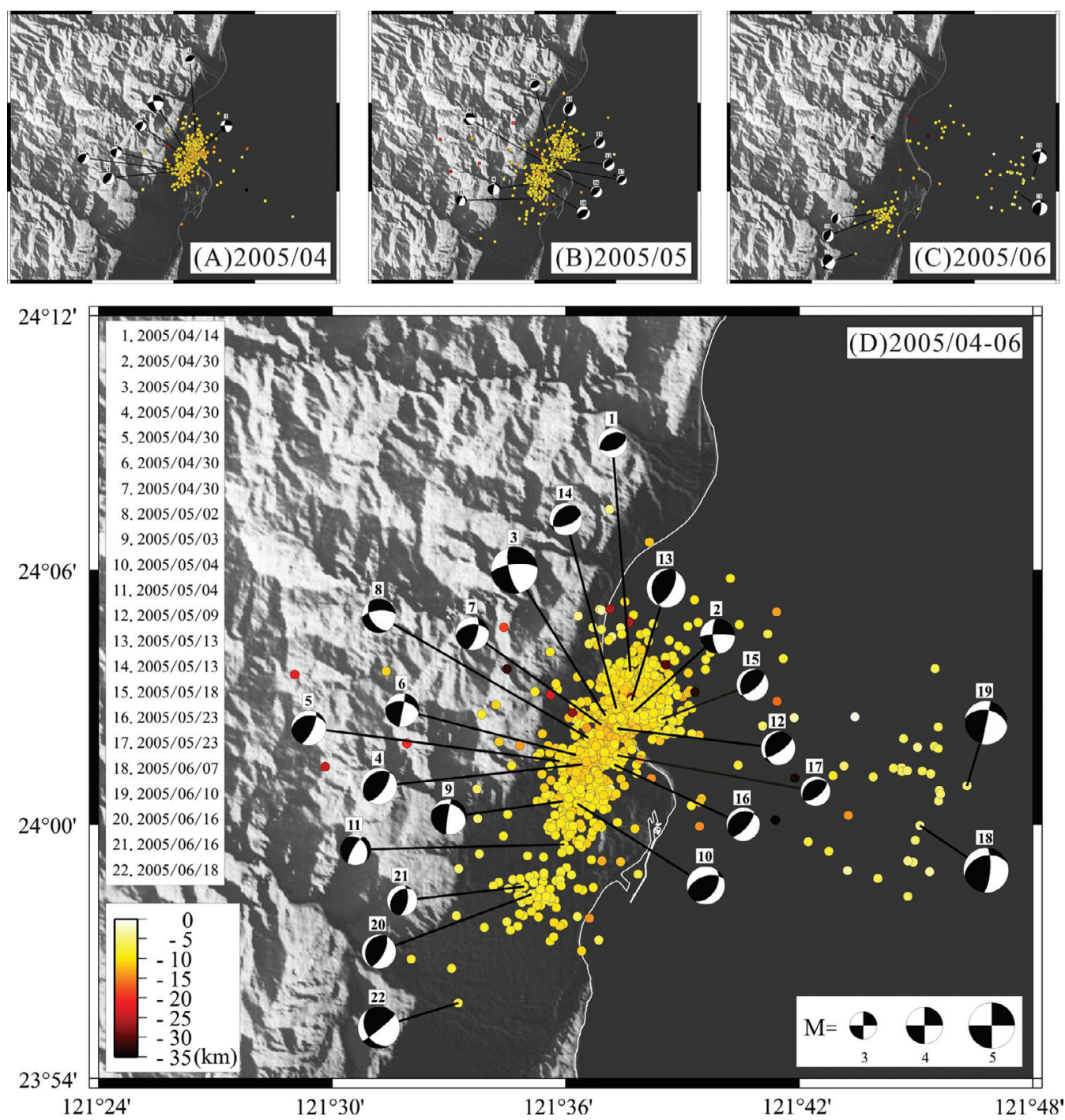

Fig. 12. Focal mechanisms of selected earthquakes in the earthquake swarm of 2004.

(1) Surface motion of May 2005 is opposite to the longer term trend in the study area, which affects the regressed mean velocity for the MTI results.

(2) Look angle correction factor: The rates from leveling ( $10 \mathrm{~mm} \mathrm{yr}^{-1}$ within Milun fault zone and $\sim 20 \mathrm{~mm} \mathrm{yr}^{-1}$ overall, whereas MTI showed $\sim 5$ and $10 \mathrm{~mm} \mathrm{yr}^{-1}$, respectively) represented the uplift rates normal to the ground. The uplift rates had to be projected to the satellite LOS direction for comparison. Envisat radar satellite has an incident angle at about $23^{\circ}$ from normal. A conversion factor of 0.92 is thus required to project the uplift rate to LOS (9.2 - $18.4 \mathrm{~mm} \mathrm{yr}^{-1}$ after projection).

(3) Line-of-sight measurement ambiguity: Radar interferometry measures the range change in the LOS direction, therefore both horizontal motions and vertical motions are projected to radar line-of-sight (Yen et al. 2008). An object moving eastwards (thus, closer to satellite) appears to be identical to the satellite compared to an object moving upwards (also closer to the satellite). GPS indicated that near Hualien City, the area to the east has a higher westward velocity than the area to the west ( $\mathrm{Yu}$ and Kuo 2001). Thus, from a radar satellite image, this area appeared to be subsiding in the eastern part and negated the uplift seen by MTI. East-west velocity difference from stations across the Milun Fault (station MELN and 0215, (Yu and Kuo 2001) is around $7 \mathrm{~mm} \mathrm{yr}^{-1}$, subsequently producing a negative $2.7 \mathrm{~mm} \mathrm{yr}^{-1}$ of LOS deformation and ultimately reducing the deformation rates measured across the Milun Fault by MTI ( $6.5 \mathrm{~mm} \mathrm{yr}^{-1}$ after accounting for horizontal motion). Although there is a significant horizontal crustal motion in eastern Taiwan (Yu and Kuo 2001), the removal of a regional range-change gradient will have a negligible effect on surface deformation measured on short $(1-2 \mathrm{~km}$ ) profiles across the fault (Hsu and Burgmann 2006). 


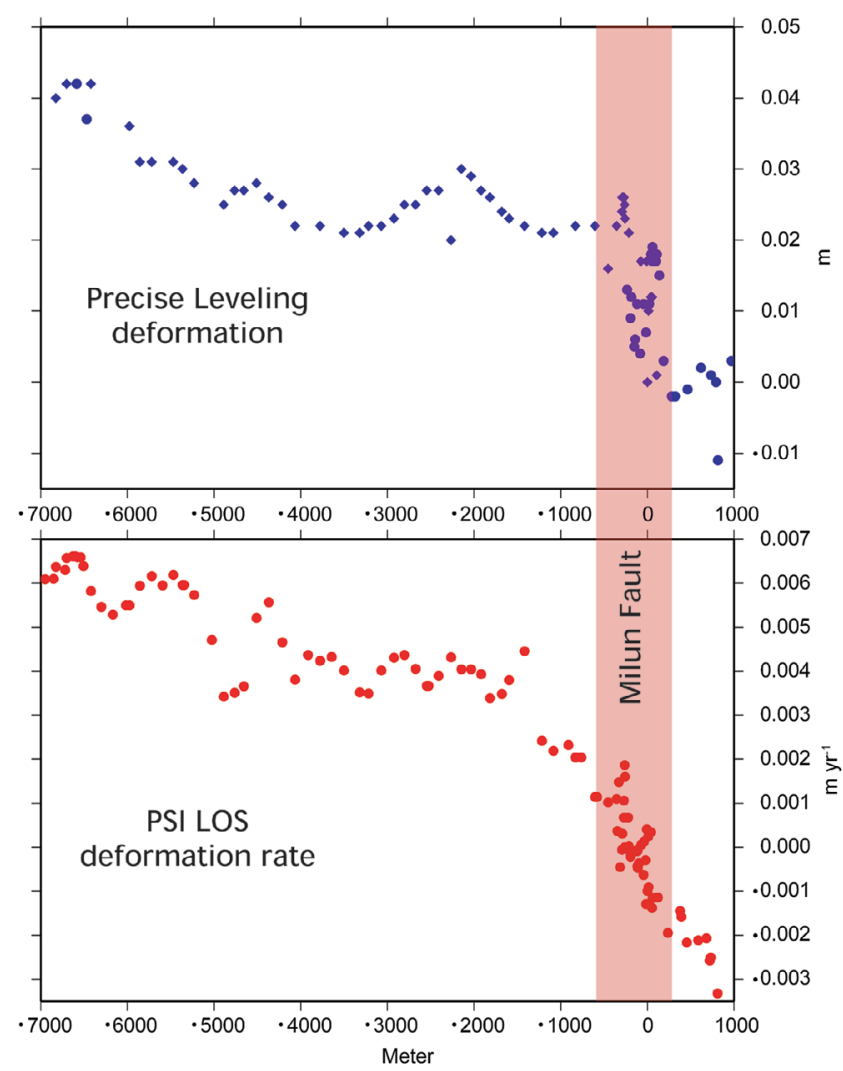

Fig. 13. Comparison of leveling and PSI results. (Top) Leveling was performed along the Milun River (yellow points in Fig. 7), (Bottom) PS data (velocity along radar LOS direction) results were sampled from the same locations as leveling with $500 \mathrm{~m}$ of radius. Both datasets were projected to an east-west direction (yellow line in Fig. 7), and R10 benchmark $\left(121.618722^{\circ} \mathrm{E}, 23.97861979^{\circ} \mathrm{N}\right)$ was set as reference point. Our results indicated that the PS and leveling results were comparable with each other.

(4) Differences in observation duration: The MTI observation lasted approximately 3.5 years, from 2004 to 2008 , which is twice the observation period of leveling (nearly 2 years). A longer observation period helps to smooth out temporally extreme values.

(5) Spatial interpolation of MTI results also slightly smoothed out the local extreme values.

Analysis of the results indicated that PSI and leveling results were well correlated and the rates, after proper adjustments, were in the same order of magnitude. Therefore, the PSI derived in this study is representative of the tectonic activities in the study area.

\subsection{Seismicity vs. Surface Deformation}

An earthquake swarm occurring near Hualien City from 4/4/2005 to 6/18/2005 was observed (Fig. 3). During this period, more than 1500 earthquake events occurred, magnitudes ranging from 1.09 to 5.62 with more than 1000 events greater than 2 (Figs. 10 and 11). On average more than 20 daily events of earthquakes occurred during this period in the study area. Although seismicity occurred before and after this period, the average number of earthquakes was approximately at $2-3$ events daily in the month before and after the earthquake swarm. Our MTI results derived from Envisat (2004 - 2008) reflected the event. Surface deformation associated with this earthquake swarm was captured by radar images taken on 2004/11/06 and 2005/06/04 . Before this image pair occurred, no earthquake was greater than magnitude 5 and only four earthquakes were greater than magnitude 4 . Whereas during this image pair, one earthquake was greater than 5 and 26 were greater than 4 . This data provided a unique opportunity to investigate both the interesting tectonic settings near Hualien City and the surface deformation and fault activities related to the earthquake swarm. Rau et al. (2007) reported several repeating earthquake sequences along the Longitudinal Valley in eastern Taiwan. These sequences consist of 25 sequences with 95 earthquake events $(2.1$ - 4.6). However, to our knowledge, no study examined the 2005 earthquake swarm near Hualien City, nor two other possible swarms in 1986 and 1995 in this area (Fig. 3).

Comparing our resulting Envisat time series (Fig. 5) with earthquake time series in the same area (Fig. 10) revealed that the deformation in the fourth image (2005/6/4) in Fig. 5 is highly correlated with the earthquake swarm near the Milun terrace. Additionally, the deformation gradient was most significant between the Beipu and Milun Fault between $1-4 \mathrm{~km}$ in the profile (Fig. 6) with the Milun terrace uplifting relative to the area to the west. The relocated earthquake in Fig. 10 collapsed to a sub-planar cluster that was trending north-northeast and dipped to the east in a high angle (profiles 3,4). Moreover, most of the focal mechanisms of the earthquake swarms were of thrust in nature. The results suggest that the 2005 earthquake swarm in the area caused the uplift.

Deformations from 2004/11/6 - 2005/6/4 and 2004/1 1/6 - 2005/9/17 as illustrated in Fig. 6 warrant further attention. By assuming that the westernmost point in profile AA' of Fig. 6 is fixed, around $15 \mathrm{~mm}$ of deformation occurred between 2004/11/6 and 2005/6/4 (Fig. 6a). We can infer that the deformation is an uplift of Milun terrace by the seismic swarm immediately before 2005/6/4. During this period, focal mechanisms of earthquakes are mostly reverse faulting (Fig. 12). According to the profile in Fig. 6b, relative deformation between 2004/11/6 - 2005/9/17 is about $12 \mathrm{~mm}$ wherein the Milun terrace is subsiding relative to the western portion of the profile. This finding also indicates a $27 \mathrm{~mm}$ relative lengthening range in the radar LOS direction between 2005/6/4 and 2005/9/17. This deformation may be attributed to the two larger earthquakes (No. 18, 19 in Fig. 12) offshore during this period. We believe that the surface deformation illustrated in Fig. 6 reflects the changes in properties of the earthquakes during the time of 
this seismic swarm. Similar displacement can be seen in the continuous GPS record shown in Fig. 14. From 2004/11/6 to $2005 / 6 / 4$, HUAL station (relative to S01R) recorded more than $20 \mathrm{~mm}$ of upward displacement. From 2005/6/4 to $2005 / 9 / 17$, approximately $20 \mathrm{~mm}$ of downward displacement was recorded (red arrows in Fig. 14). Thus, if a geodetic procedure were performed to investigate the change between 2004/11/6 and 2005/9/17, there would be very little deformation. This complements the MTI results in this study. However, further works are necessary to understand how these two earthquakes and the observed deformation during this period are related. The western extent of coseismic deformation shown in Fig. 6a is mostly following along the Beipu Fault and southern part of the Milun Fault. The topographic relief across the Beipu Fault is on the order of $10 \mathrm{~m}$, while the topographic relief along the Milun Fault is larger (in tens of meters). Although it is not impossible, the chance that an atmosphere effect follows these fault traces of low topographic relief is small.

\subsection{Current States of Active Tectonics in the Northern Longitudinal Valley near Hualien City}

Our field investigation in the study area indicated that many fractures developed in man-made structures near the known fault traces in Hualien City. However, these fractures apparently did not grow over time, or at least, did not constantly grow over time. Within the time frames of our dataset, the first order surface deformation is the gentle uplift gradient shown in profiles A, B, C, and D in Fig. 9. The relative uplift rate from our results revealed that between the western and eastern Longitudinal Valley near Hualien City is approximately $1 \mathrm{~cm} \mathrm{yr}^{-1}$ from 1995 to 2008. Although earthquakes and earthquake swarm contributed to surface deformation as illustrated in Fig. 6, the longer term effects of earthquakes on surface deformation around Hualien City is of a second order compared to the first order deformation mentioned above. Moreover, the deformation associated with the earthquakes may be spatially dispersed, rather than concentrated near the fault lines.

\section{CONCLUSIONS}

Through integrating PS- and SB- InSAR, we show that multi-temporal InSAR is a highly effective procedure in extracting surface deformation signals. The results also reveal complex neotectonic activities in the study area. Based on the results of this study, we can conclude:

(1) Integrating PS- and SB- InSAR was a highly effective means of extracting deformation signals, even in suburban areas. The high spatial density observation and multi-temporal observation of PS/SB InSAR can also complement other geodetic procedures such as GPS and

\section{HUAL}

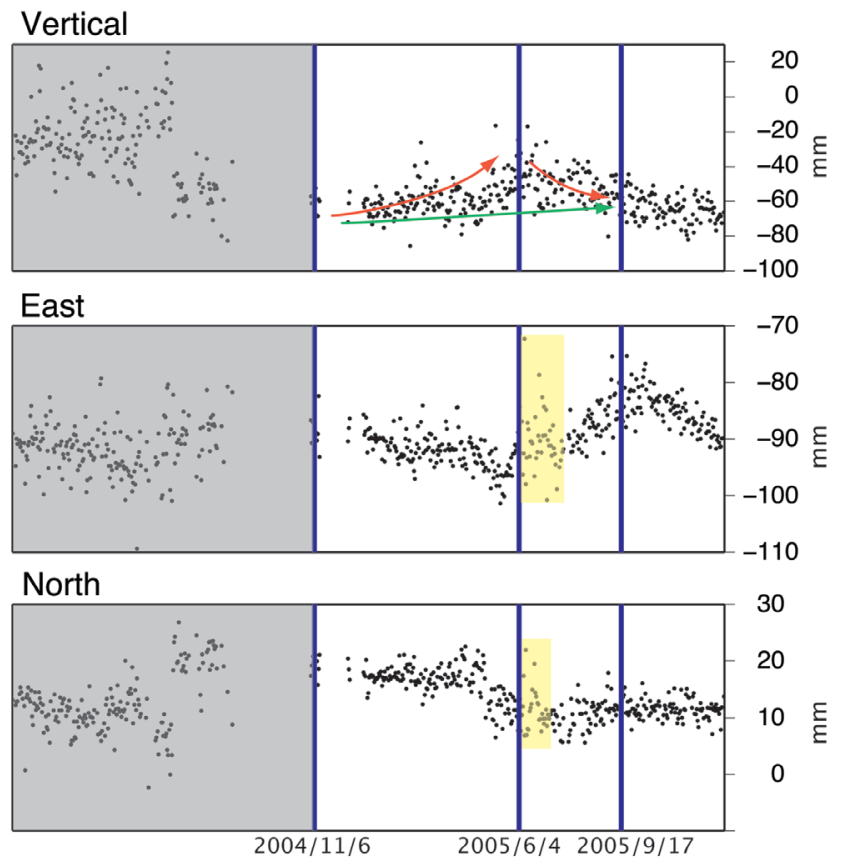

Fig. 14. Continuous GPS records of HUAL station between 2004 and 2005 near Hualien City. GPS Velocity is relative to S01R. Data from DMC, Institute of Earth Sciences, Academia Sinica.

leveling. The deformation signals from PS/SB InSAR were comparable with those of the leveling data;

(2) In the northern Longitudinal Valley and Hualien City, during the time spans of our dataset, we found that the most active structure was the Mingyi Fault. Areas near the Central Range and Milun terrace were generally uplifting relative to Hualien City, while the northern end of Coastal Range was subsiding relative to the Longitudinal Valley;

(3) Fault systems in the Milun Terrace apparently did not extend southwards into the Longitudinal Valley;

(4) Data from the deformation time series of the Envisat dataset was able to capture the small magnitude coseismic deformation signal of the earthquake swarm in mid 2005; and

(5) The relocated earthquakes collapsed into a sub-planar surface trending north-northeast, which does not entirely coincide with the Milun Fault.

Acknowledgements The authors would like to thank the National Science Council of the Republic of China, Taiwan, for financially supporting this research under Contract No. NSC 98-2116-M-259-002-. ENVISAT data was provided by ESA under the project of Earth Observation (contract No. EOPI-4427). We are grateful to three anonymous reviewers for their comments and suggestions that greatly improve the manuscript. 


\section{REFERENCES}

Angelier, J., H. T. Chu, and J. C. Lee, 1997: Shear concentration in a collision zone: Kinematics of the Chihshang Fault as revealed by outcrop-scale quantification of active faulting, Longitudinal Valley, eastern Taiwan. Tectonophysics, 274, 117-143, doi: 10.1016/ S0040-1951(96)00301-0. [Link]

Berardino, P., G. Fornaro, R. Lanari, and E. Sansosti, 2002: A new algorithm for surface deformation monitoring based on small baseline differential SAR interferograms. IEEE Trans. Geosci. Remote Sensing, 40, 23752383, doi: 10.1109/TGRS.2002.803792. [Link]

Chang, C. P., C. T. Wang, T. Y. Chang, K. S. Chen, L. S. Liang, E. Pathier, and J. Angelier, 2004: Application of SAR interferometry to a large thrust deformation: the $1999 M_{w}=7.6$ Chichi earthquake in central Taiwan. Geophys. J. Int., 159, 9-16, doi: 10.1111/j.1365246X.2004.02385.x. [Link]

Ferretti, A., C. Prati, and F. Rocca, 2000: Nonlinear subsidence rate estimation using permanent scatterers in differential SAR interferometry. IEEE Trans. Geosci. Remote Sensing., 38, 2202-2212, doi: 10.1109/36.868878. [Link]

Ferretti, A., C. Prati, and F. Rocca, 2001: Permanent scatterers in SAR interferometry. IEEE Trans. Geosci. Remote Sensing, 39, 8-20, doi: 10.1109/36.898661. [Link]

Hooper, A., 2008: A multi-temporal InSAR method incorporating both persistent scatterer and small baseline approaches. Geophys. Res. Lett., 35, L16302, doi: 10. 1029/2008GL034654. [Link]

Hooper, A. and H. A. Zebker, 2007: Phase unwrapping in three dimensions with application to InSAR time series. JOSA A, 24, 2737-2747, doi: 10.1364/JOSAA.24. 002737. [Link]

Hooper, A., P. Segall, and H. Zebker, 2007: Persistent scatterer interferometric synthetic aperture radar for crustal deformation analysis, with application to Volcán Alcedo, Galápagos. J. Geophys. Res., 112, B07407, doi: 10.1029/2006JB004763. [Link]

Hsu, L. and R. Bürgmann, 2006: Surface creep along the Longitudinal Valley fault, Taiwan from InSAR measurements. Geophys. Res. Lett., 33, L06312, doi: 10. 1029/2005GL024624. [Link]
Kampes, B. M., 2006: Radar Interferometry: Persistent Scatterer Technique. Springer, 211 pp.

Lu, Y. F., 2007: Monitoring surface subsidence of Yunlin using radar interferometry. Master Thesis, National Chiao Tung University, Hsinchu, Taiwan.

Lyons, S. and D. Sandwell, 2003: Fault creep along the southern San Andreas from interferometric synthetic aperture radar, permanent scatterers, and stacking. $J$. Geophys. Res., 108, 2047, doi: 10.1029/2002JB001831. [Link]

Rau, R. J., K. H. Chen, and K. E. Ching, 2007: Repeating earthquakes and seismic potential along the northern Longitudinal Valley fault of eastern Taiwan. Geophys. Res. Lett., 34, L24301, doi: 10.1029/2007GL031622. [Link]

Rosen, P. A., S. Henley, G. Peltzer, and M. Simons, 2004: Updated Repeat Orbit Interferometry Package Released. Eos, Trans., AGU, 85, doi: 10.1029/20 04EO050004. [Link]

Waldhauser, F. and W. L. Ellsworth, 2000: A doubledifference earthquake location algorithm: Method and application to the northern Hayward fault, California. Bull. Seismol. Soc. Am., 90, 1353-1368, doi: 10.1785/0120000006. [Link]

Wright, T. J., B. E. Parsons, J. A. Jackson, M. Haynes, E. J. Fielding, P. C. England, and P. J. Clarke, 1999: Source parameters of the 1 October 1995 Dinar (Turkey) earthquake from SAR interferometry and seismic bodywave modelling. Earth Planet. Sci. Lett., 172, 23 37, doi: 10.1016/S0012-821X(99)00186-7. [Link]

Yang, S. H., 1999: Inverting fault location from geodetic measurements - Hualien. Master Thesis, National Central University, Jhong-li, Taiwan, 100 pp.

Yen, J. Y., K. S. Chen, C. P. Chang, and W. M. Boerner, 2008: Evaluation of earthquake potential and surface deformation by Differential Interferometry. Remote Sens. Environ., 112, 782-795, doi: 10.1016/j.rse.2007. 06.012. [Link]

Yu, S. B. and L. C. Kuo, 2001: Present-day crustal motion along the Longitudinal Valley Fault, eastern Taiwan. Tectonophysics, 333, 199-217, doi: 10.1016/S0040-19 51(00)00275-4. [Link]

Yu, S. B., H. Y. Chen, and L. C. Kuo, 1997: Velocity field of GPS stations in the Taiwan area. Tectonophysics, 274, 41-59, doi: 10.1016/S0040-1951(96)00297-1. [Link] 